\title{
Resenha \\ Culturas da Infância: A Contribuição de Heidi Keller
}

\author{
Keller, H. (2007). \\ Cultures of infancy: Heidi Keller's Contribution. \\ Mahwah, NJ: Lawrence Erlbaum Associates.
}

\author{
Ana Paula Kobarg, Gabriela Dal Forno Martins \& Mauro Luís Vieira* \\ Universidade Federal de Santa Catarina
}

Diversas abordagens científicas atuais têm enfatizado a importância do contexto na compreensão dos fenômenos investigados. Não só na Psicologia, como também nas demais áreas do conhecimento, como na Biologia e na Física, têm-se verificado rupturas paradigmáticas, no sentido de não só estudar os fenômenos isolados ou em partes, mas sim compreender as relações entre suas partes constituintes, tendo como pano de fundo um contexto maior.

Mais especificamente na Psicologia do Desenvolvimento Humano, essas idéias têm influenciado algumas abordagens atuais, tais como a Psicologia do Desenvolvimento Evolucionista. Heidi Keller, autora do livro recentemente publicado "Cultures of infancy" (2007), apresenta a concepção de desenvolvimento humano adotada por esta perspectiva, bem como sistematiza resultados de diversos estudos atuais realizados em diferentes sociedades ocidentais e orientais, urbanas e rurais, que têm contribuído tanto para confirmar pressupostos iniciais, quanto para introduzir novas descobertas na área do desenvolvimento humano.

Logo no prefácio do livro, a autora introduz a noção de desenvolvimento adotada pela perspectiva Evolucionista, afirmando que as trajetórias relacionadas ao desenvolvimento são consideradas soluções culturais para resolver tarefas de desenvolvimento que são comuns aos seres humanos. Com relação aos aspectos universais, Keller explica que certos comportamentos presentes ao longo da trajetória de desenvolvimento evoluíram no sentido de resolver problemas de adaptação que ocorreram durante a história filogenética da espécie humana. Dessa forma, o desenvolvimento é entendido como resultado da interação entre a herança biológica e aspectos culturais específicos, rejeitando o determinismo biológico e enfatizando relações transacionais entre o organismo e o ambiente.

O livro é organizado em nove capítulos, sendo o último deles reservado para sínteses e conclusões. Para melhor apresentação do livro, os oito capítulos foram organizados em três grandes partes. A primeira inclui os três primeiros

* Endereço para correspondência: Universidade Federal de Santa Catarina, Departamento de Psicologia, Campus Universitário, Trindade, Florianópolis, SC, Brasil, CEP 88040-900. Tel.: (48) 3721 8606.E-mail: mvieira@ cfh.ufsc.br capítulos e aborda aspectos teóricos relacionados à infância, como sua concepção, o processo de desenvolvimento e aprendizagem, e aspectos biológicos e culturais constituintes desses fenômenos. A segunda parte inclui o capítulo quarto e apresenta diferentes recursos metodológicos para estudo da infância. Por fim, na última parte do livro, composta pelos capítulos 5, 6, 7 e 8, a autora apresenta os modelos culturais de parentalidade, bem como as repercussões desses diferentes modelos no desenvolvimento das crianças, através da sistematização de resultados de pesquisas realizadas em diferentes regiões do mundo.

No Capítulo 1, a autora caracteriza a fase de desenvolvimento da infância em termos de: longo período de imaturidade, alto grau de aprendizagem necessária para a inserção no grupo social e importância das relações iniciais com cuidadores. Já no segundo capítulo, Keller apresenta o estado da arte relacionado às pesquisas sobre a psicobiologia da infância, descrevendo detalhadamente o modelo teórico Evolucionista que evidencia o desenvolvimento através das relações sociais na infância, sobretudo com os cuidadores primários.

A partir do terceiro capítulo, Keller passa a apresentar variações dos modelos de parentalidade entre diversas culturas. Dessa forma, no Capítulo 3 o conceito de cultura é definido em termos de práticas e sistemas de significados compartilhados entre ambientes sociodemograficamente delimitados. A cultura é considerada o modo primário de adaptação humana e, dessa forma, o desenvolvimento consiste na construção e co-construção dos aparatos culturais levando em consideração as predisposições biológicas. A autora destaca que a estrutura socioeconômica de uma sociedade, incluindo a base da economia familiar e seu padrão social, define as estratégias de socialização, as quais consistem nas idéias e nas práticas que influenciam diretamente o desenvolvimento das crianças e, conseqüentemente, a psicologia do adulto.

O quarto capítulo apresenta aspectos metodológicos relacionados ao recrutamento dos participantes dos estudos e aos procedimentos de coleta de dados. Com relação a este último aspecto, a autora apresenta uma riqueza de possibilidades, uma vez que utiliza em suas pesquisas diferentes métodos para avaliar diferentes dimensões, 
especialmente questionários, entrevistas, observações naturalísticas ou filmagens. As possibilidades de análises também são vastas, incluindo análises estatísticas variadas e análises qualitativas do material verbal coletado. Segundo Keller, somente a combinação de métodos permite que se apreenda um maior número de variáveis do fenômeno, possibilitando uma compreensão mais ampla do mesmo.

Na última parte do livro, a partir do Capítulo 5, a autora descreve tipos de comportamento de cuidado parental observados e estudados em diversas comunidades, caracterizando contextos urbanos e rurais, para demonstrar um mecanismo significativo na transmissão de valores e de práticas culturais entre gerações. Keller apresenta em seu trabalho duas trajetórias ontogenéticas típicas, uma ocidental (que a autora caracteriza como típica de sociedades urbanas) e outra não-ocidental (não urbana, que ocorre principalmente em comunidades rurais), relacionadas a dois modos específicos de investimento parental. No modo nãoocidental, o cuidado físico inclui a amamentação por dois a quatro anos, o bebê é carregado, em média, mais do que $50 \%$ do tempo, o contato corporal se dá durante o dia e a noite (nas costas, na frente ou no quadril da mãe), as crianças dormem com os adultos e os cuidados extras são oferecidos por outros parentes e irmãos da criança. Paralelamente, neste modo de investimento parental, o cuidado emocional apóia uma longa simbiose com a mãe e se caracteriza por longos períodos de contato e comunicação corporal, que ocorrem conjuntamente a outras atividades do adulto.

Por outro lado, no modo ocidental, o cuidado físico é caracterizado por um período de amamentação em média bem mais curto (de um a três meses), por reduzidos períodos de carregar o bebê, principalmente em resposta a seu choro, e por pouco contato corporal, ficando o bebê principalmente no berço e em carrinhos. Os cuidados extras oferecidos são geralmente pagos (ex: babás, creches). Quanto ao cuidado emocional, ele promove a independência precoce e envolve períodos curtos de cuidados exclusivos e de episódios face-a-face.

No Capítulo 6 são analisadas possibilidades de combinações múltiplas entre dois modelos culturais de cuidado parental: Interdependência e Independência. Uma outra possibilidade refere-se ao modelo denominado autônomorelacional, o qual compreende características combinadas de ambos os modelos anteriores. Esse tipo de orientação cultural engloba autonomia e relação, em que o self é definido como autônomo quanto à sua ação e relacional quanto à proximidade interpessoal. Ele é característico de famílias de classe média, urbana e escolarizada em sociedades tradicionalmente interdependentes.

A variação dos modelos prototípicos ocorre quando se analisa o nível educacional num mesmo meio ambiente cultural. As pesquisas demonstram que, mesmo havendo predomínio de um modelo cultural, as mães podem diferir com relação à ênfase na autonomia ou relação, dependendo de seu nível de escolaridade. Keller evidencia ainda que mudanças históricas, tais como a globalização e a moder- nização, orientam um crescimento em direção a modelos culturais mais independentes. Por último, a autora destaca que as mudanças geracionais também contribuem para mudanças nos modelos culturais. Isso fica evidenciado principalmente na observação do comportamento parental de diferentes gerações, uma vez que o discurso tende a ser mais semelhante em função da busca pela coesão familiar.

Teoricamente, supõe-se que todas estas dimensões do cuidado parental estejam relacionadas e se complementando para definir o modelo cultural de ambientes específicos. Para comprovar esta suposição, foi analisado no Capítulo 7 a inter-relação entre estas dimensões. Através das diferentes análises apresentadas neste capítulo conclui-se que: (a) as diferentes dimensões do modelo teórico são aspectos centrais do modelo cultural; (b) estas dimensões diferentes dão forma a métodos padronizados de pesquisa; e (c) embora todas estas dimensões se relacionem de maneira significativa, cada uma delas carrega o conhecimento cultural que é específico a este domínio.

No Capítulo 8, Keller aborda as conseqüências desenvolvimentais de experiências parentais precoces. $\mathrm{O}$ conceito de tempo de vida desenvolvimental está baseado na suposição de que há tarefas desenvolvimentais universais que tem evoluído e que têm sido resolvidas de diferentes maneiras, dependendo de uma cultura específica, a fim de representar adaptações para um contexto ecocultural particular. São esperados comportamentos específicos em idades precoces das crianças, dependendo dos padrões de cada cultura.

Através da descrição dos temas tratados nos capítulos, pode-se constatar que a autora contribui de forma teórica e prática para a compreensão e desenvolvimento de pesquisas avaliando as conseqüências da cultura no cuidado parental e suas tarefas desenvolvimentais. Com base nas idéias inovadoras apresentadas no livro, que indicam caminhos teóricos e metodológicos consistentes, pode-se afirmar que o livro de Keller é uma obra que vale a pena ser lida. Como o livro ainda não foi traduzido para o português, os esforços daqueles que não estão muito familiarizados com o inglês é recompensado. Ou seja, Keller, em sua monumental obra, traz uma riqueza de contribuições no sentido de permitir pensar de que forma a cultura e a biologia podem estar relacionadas e não colocadas em pólos opostos. Esta é uma tendência atual no estudo da Psicologia do Desenvolvimento.

\section{Referência}

Keller, H. (2007). Cultures of infancy: Heidi Keller's Contribution. Mahwah, NJ: Lawrence Erlbaum Associates. 